\title{
Preparation and properties of polystyrene incorporated with gold and silver nanoparticles for optoelectronic applications
}

\author{
Raid A. Ismail ${ }^{1}$ Nahida J. Almashhadani ${ }^{1} \cdot$ Rand H. Sadik $^{1}$
}

Received: 21 January 2017/ Accepted: 14 February 2017/Published online: 2 March 2017

(C) The Author(s) 2017. This article is published with open access at Springerlink.com

\begin{abstract}
In this paper, methyl-orange-doped polystyrene (PS) microspheres covered with gold and silver nanoparticles (NPs) have been synthesized. The optical and structural properties of the porous polystyrene films before and after incorporation of $\mathrm{Au}$ and $\mathrm{Ag}$ nanoparticles were investigated using X-ray diffraction (XRD), scanning electron microscope (SEM), atomic force microscope (AFM), Fourier transformation infrared spectrophotometer (FT-IR), and UV-Vis spectrophotometer. The optical data showed that the optical energy gap of PS film was increased from 2 to $3.4 \mathrm{eV}$ and to $3.5 \mathrm{eV}$ after being filled with $\mathrm{Ag}$ and $\mathrm{Au}$ nanoparticles, respectively. The electrical and photoresponse properties of $\mathrm{Ag}-\mathrm{PS} / \mathrm{p}-\mathrm{Si}$ and $\mathrm{Au}-\mathrm{PS} / \mathrm{p}-$ $\mathrm{Si}$ heterojunctions were studied. The rectification characteristics of the junction were improved after nanoparticle incorporation. The photoresponse results confirm the presence of two peaks of response located at 450 and $900 \mathrm{~nm}$. The Au-PS/Si heterojunction gave the best photosensitivity.
\end{abstract}

Keywords Polystyrene · Incorporation · Gold nanoparticles $\cdot$ Silver nanoparticles

\section{Introduction}

Organic polymer-based materials are very important in the field of optoelectronics due to their attractive properties (Hsu et al. 2016). These materials are rapidly

Raid A. Ismail

raidismail@yahoo.com

1 Department of Applied Science, University of Technology, Baghdad, Iraq replacing their inorganic counterparts due to their flexibility in manufacturing combined with the ease in fabrication and manufacturing. Polystyrene (PS) has draw attention due to its superior properties such as high transparency, electrical insulator, high refractive index and low water absorption (Shaffer and Koziol 2002; Walker and Asher 2005). PS being cost-effective commercial commodity plastic material has been utilized as one of the important polymeric materials for various NLO-active devices (Sureshkumar et al. 2008). It is reported that the optical properties, magnetic properties, and mechanical properties of PS were significantly improved after embedding metal or semiconductor nanoparticles into the polymer matrix (Nikkeshi et al. 1998; Zhu and Schmauder 2003; Ahmad and Mamat 2011; Aly et al. 2012; Sangawar and Golchha 2013). It is reported that addition of metal nanoparticles can enhance the thermal conductivity and heat transfer of fluid (Sheikholeslami 2017a, b; Sheikholeslami et al. 2017; Sheikholeslami and Vajravelu 2017). Incorporation of noble metals in polystyrene for the synthesis of composite has potential advantages in optoelectronic, catalyst, and chemical sensors applications (Alekseeva et al. 2013; Zhu et al. 2013; Khokhar et al. 2011; Higuchi et al. 2016). Xia et al. (2014) increased the power conversion efficiency of organic/Si hybrid solar cells by incorporating of gold into poly (3,4-ethylenedioxythiophene)/polystyrenesulfonate due to light trapping.

Here, we report the first study on preparation and characterization of $\mathrm{PS}: \mathrm{MO} / \mathrm{Si}$ heterojunction photo detectors based on incorporating the polystyrene with gold and silver nanoparticles prepared by laser ablation in liquid. 


\section{Experimental}

In this study, we used high-purity polystyrene grains provided from by the ICI company as matrix, first the PS grains dissolved in high-purity $(99.99 \%)$ dimethylene chloride $\left(\mathrm{CH}_{2} \mathrm{Cl}_{2}\right)$ solvent provided from $\mathrm{GCC}$ to obtain concentration of $7 \mathrm{wt} \% / \mathrm{vol}$. PS was doped with methylorange (MO) $\left(\mathrm{C}_{14} \mathrm{H}_{14} \mathrm{~N}_{3} \mathrm{NaO}_{3} \mathrm{~S}\right)$ with concentration of 6.7 $\mathrm{wt} \%$. Figure 1 shows the photograph of PS solution before and after doping with MO. The colloidal silver NPs (Fig. 2) were synthesized by laser ablation in ethanol with laser energy of $750 \mathrm{~mJ}$ and with 200 laser pulses, while the $\mathrm{Au}$ NPs were synthesized with laser energy of $600 \mathrm{~mJ}$ with 300 laser pulses. The concentration of Ag and Au NPs was 0.4 and $0.5 \mathrm{mg} \mathrm{mL}^{-1}$, respectively. The experimental details of laser ablation process of $\mathrm{Au}$ nanoparticles are presented elsewhere (Ismail et al. 2012; Yong et al. 2006). Incorporating the $\mathrm{Ag}$ and $\mathrm{Au}$ NPs into the PS matrix was carried out using drop casting technique. The structure of the doped polystyrene before and after nanoparticle incorporation was investigated using X-ray diffractometer (XRD-6000 Shimadzu). Scanning electron microscope (FEI, model) was used to investigate the microstructure and pore size of PS. Transmission electron microscope (Philips CM10 pw 6020) was used to investigate the morphology and size of $\mathrm{Au}$ and $\mathrm{Ag}$ NPs. The functional group of PS was measured using FT-IR (FTIR-8400s, Shimadzu) spectrophotometer. The optical absorption of films was measured by using UV-Vis spectrophotometer (UV/1800, Shimadzu). Atomic force microscopy (CSPM-5000) was used to investigate the surface morphology of the PS. To fabricate photodetector, drop casting technique was used to deposit the PS film on a $1-\mathrm{cm}^{2}$ mirror-like $p$-type (111) single-crystal silicon substrates having electrical resistivity of 1-3 $\Omega \mathrm{cm}$. Ohmic contacts were made on PS and on back surface of the silicon substrate by depositing indium and aluminum films, respectively, using thermal

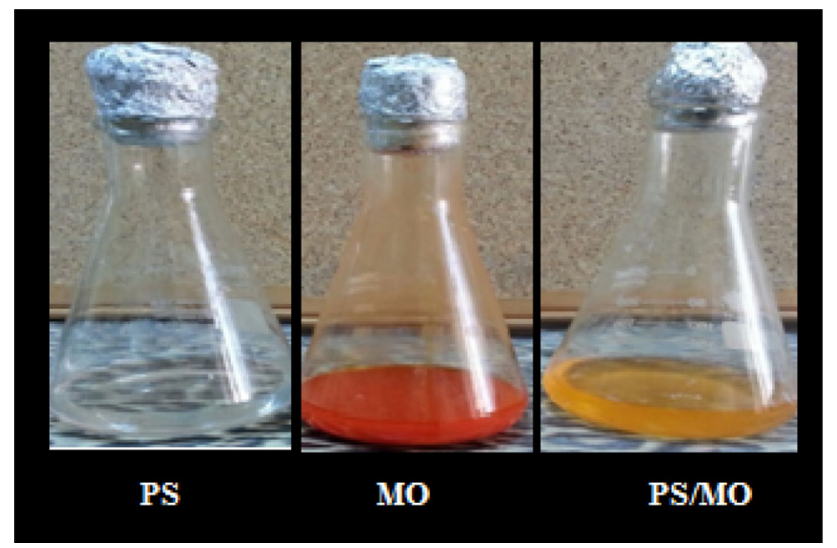

Fig. 1 Photographs of polystyrene solution before and after doping with MO

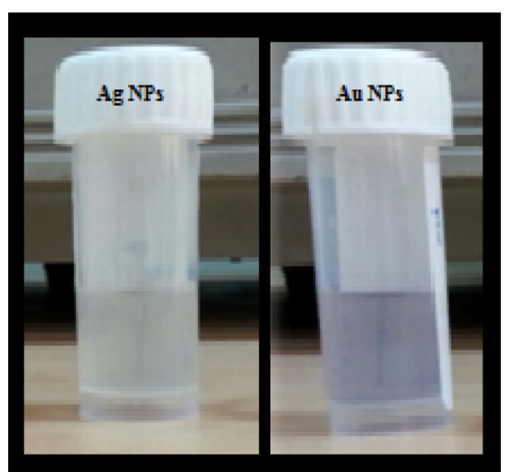

Fig. 2 Photograph of fresh colloidal Ag NPs and Au NPs prepared by laser ablation in ethanol

evaporation system under pressure down to $10^{-7} \mathrm{mbar}$; Fig. 3 shows the schematic diagram of PS/p-Si heterojunction. The dark and illuminated current-voltage characteristics were investigated.

The spectral responsivity in the range of (400-1000) nm of the heterojunctions before and after incorporation of nanoparticles was investigated using calibrated monochromator (Jobin-Yvon). All the above measurements were conducted at room temperature.

\section{Results and discussion}

Figure 4 shows XRD patterns of PS film before and after incorporated with nanoparticles. A broad and strong peak was noticed at $\sim 20^{\circ}$ indicating the amorphous nature of PS even after incorporating the $\mathrm{Ag}$ and $\mathrm{Au}$ nanoparticles into the PS matrix. A small shift in $2 \theta$ and increase in diffraction peak intensity were observed after adding these nanoparticles.

Figure 5 shows the SEM images of PS matrix and Au/ PS and Ag/PS composite surfaces. The SEM image confirmed the formation of high-porosity ( $\sim 94 \%)$ PS structure; the pores have circular shape with an average size of

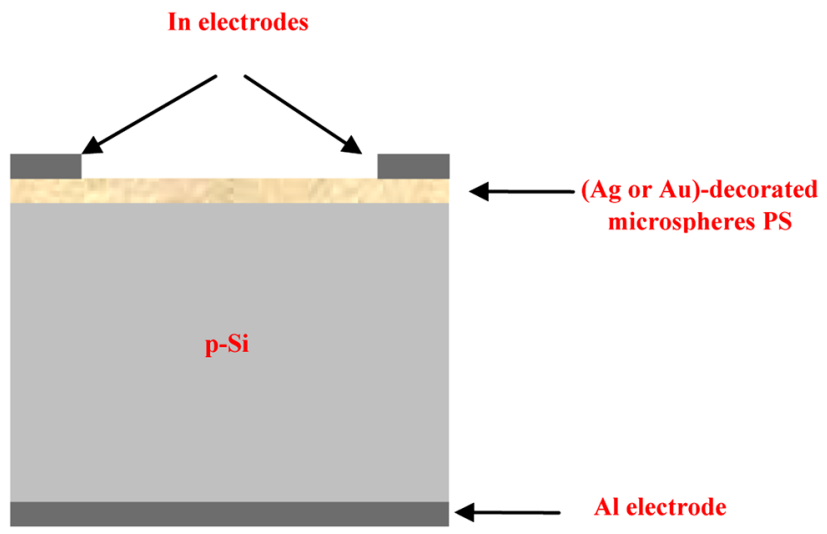

Fig. 3 Architecture of PS/Si heterojunction 


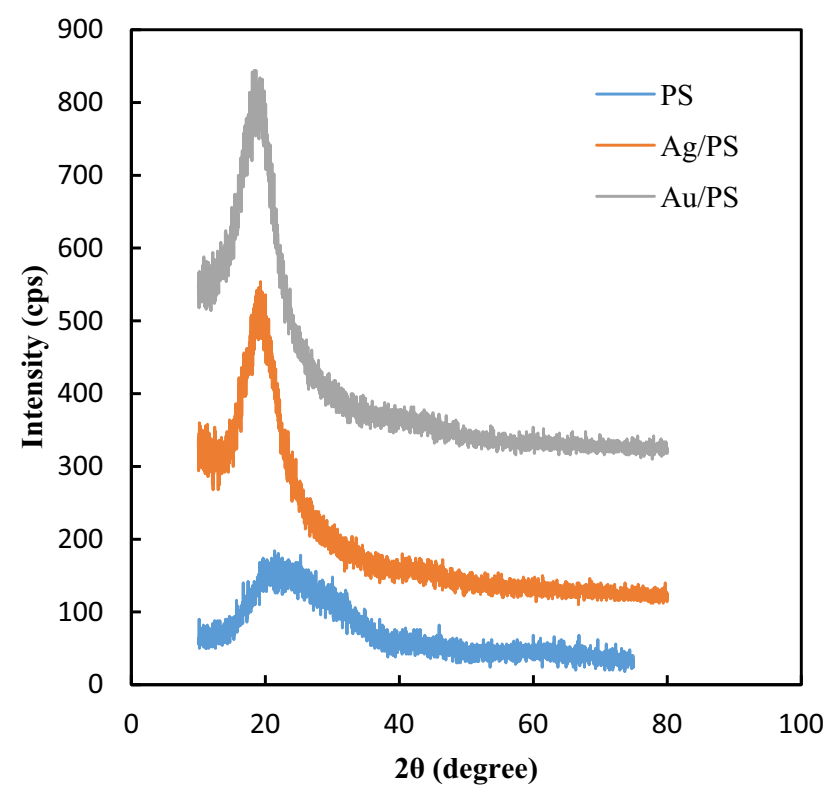

Fig. 4 XRD patterns of PS films before and after addition of Au and Ag nanoparticles

$5.5 \mu \mathrm{m}$. The PS surface (Fig. 5a) exhibits highly interconnected micropore structure. After addition of $\mathrm{Au}$ and $\mathrm{Ag}$ nanoparticles, the PS surface was modified and the pores were completely filled with these nanoparticles as seen in Fig. 5b, c. It is obvious from this figure PS microspheres were covered with $\mathrm{Au}$ and Ag nanoparticles. These structures indicate gold-decorated and silver-decorated microspheres increasing the coverage area of both $\mathrm{Au}$ and Ag on the PS core (Zhang et al. 2006).

In the inset of Fig. 5c, we have observed formation of silver nanoshells as well as free silver nanoparticles attached on PS surfaces. This process mainly depends on the growth and nucleation conditions (Zhang et al. 2006), and the same thing was noticed for Au-PS composite structure. Figure 6 shows the TEM images of Au NPs and Ag NPs prepared by laser ablation in ethanol. It is clearly seen that the particles were in nano-size and have spherical shape. The average particle sizes of $\mathrm{Au}$ and $\mathrm{Ag}$ were around 50 and $70 \mathrm{~nm}$, respectively. Agglomeration and aggregation of gold NPs and Ag NPs have been observed (denoted by arrows).

This agglomeration can be arising from the heating induced by high laser fluence which in turn affects the surface chemistry of the Au and Ag NPs and plays an important role in dynamic procedure of agglomeration (Zhang and $\mathrm{Gu}$ 2006). Hydrodynamic drag force $\left(\mathrm{F}_{\mathrm{d}}\right)$ produced from laser heating of nanoparticles solution resulted in a circulation of the fluid which can also contribute to the agglomeration of nanoparticles. The drag force can be given by the following equation (Grant et al. 2003; Khodary 2010):
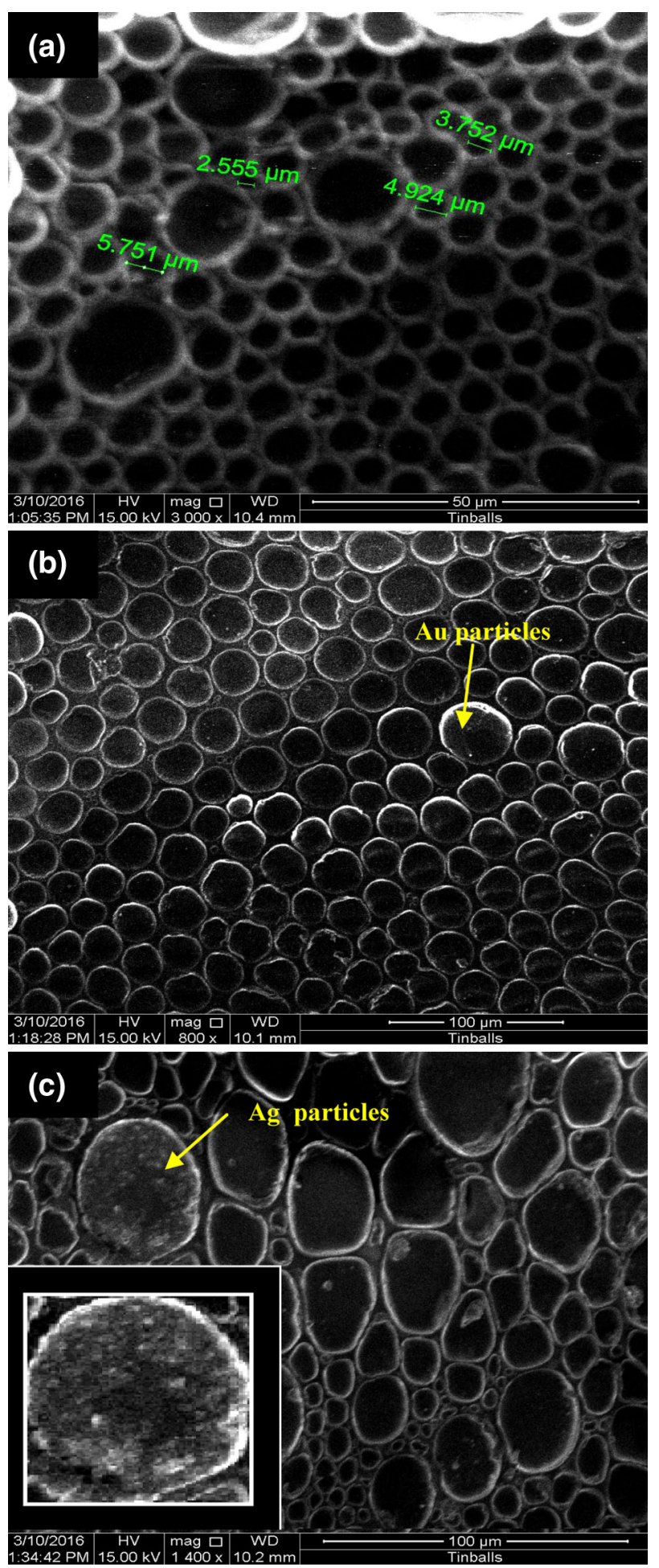

Fig. 5 SEM images of a PS matrix, b Au-incorporated PS matrix, c Ag-incorporated PS matrix. Inset the magnified SEM image of microsphere PS

$F_{\mathrm{d}}=\frac{1}{2} C_{\mathrm{d}} A \rho V^{2}$,

where $C_{\mathrm{d}}$ is the drag coefficient, $A$ is the cross-sectional area of perpendicular on ethanol flow, $\rho$ is the density of

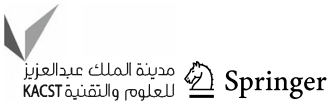


Fig. 6 TEM images of Au NPs (a) and Ag NPs (b)
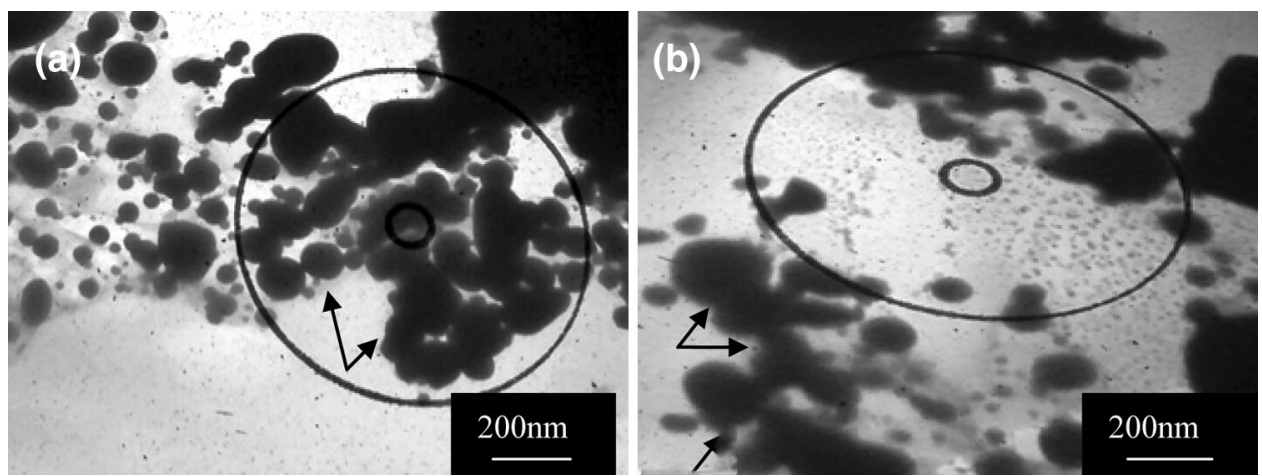

ethanol and $V$ is the velocity of colloidal solution. The morphology of PS, Au-Ps and Ag-PS composites was investigated by AFM. Figure 7 shows 3D-AFM images (scanned area of $3 \times 3 \mu \mathrm{m}$ ) of PS before after incorporation of $\mathrm{Au}$ and $\mathrm{Ag}$ NPs.

The PS matrix film has pores and the grains agglomerated and aggregated on the walls of the pores. It is clear that the morphology of PS showed microspheres of PS with existence of pores (Fig. 7a). The morphology was significantly changed after adding the nanoparticles; the added particles completely filled the PS-interconnected pores and some of them are agglomerated. The AFM images of AuPS and Ag-PS composites (Fig. 7b, c) confirmed that the $\mathrm{Au}$ and $\mathrm{Ag}$ particles were uniformly distributed over the entire PS matrix, vertically aligned and well attached to the PS microspheres.

The root-mean square (RMS) of surface roughness was obtained from AFM analysis and found to be 0.29, 0.65 and $0.55 \mathrm{~nm}$ for PS, Au-PS and Ag-PS films, respectively. Increasing the surface roughness will enhance the light absorption in photodetector applications. The optical band gap $\left(E_{\mathrm{g}}\right)$ of PS films can be obtained from the Tauc relationship:

$(\alpha h v)=A\left(E_{\mathrm{g}}-h v\right)^{1 / 2}$,

where $A$ is a constant, $\alpha$ is the absorption coefficient, and $h v$ is the photon energy. Figure 8 shows the $(\alpha h v)^{2}$ versus photon energy plots for PS and $\mathrm{Au}-\mathrm{PS}$ and $\mathrm{Ag}-\mathrm{PS}$ composite films. Figure 8 proves that the transition type is direct, the optical band gap can be determined from extrapolating the linear part of this figure to $h v=0$ points. The energy gap of PS:MO was found to be around $4.5 \mathrm{eV}$. Incorporating of PS with Au NPs and Ag NPs resulted in decreasing the band gap to 3.5 and $3.3 \mathrm{eV}$, respectively. The variation of the optical energy gap after adding nanoparticles can be attributed to modifying the electronic structure of the PS matrix due to appearance of various polaronic and defect levels (Costa et al. 1998) due to decreasing the electrical resistivity of PS. Our results showed that the electrical resistivity of PS was decreased from $4.59 \times 10^{6} \Omega \mathrm{cm}$ to $3.7 \times 10^{5} \Omega \mathrm{cm}$ and to $2.1 \times 10^{5} \Omega \mathrm{cm}$ after inclusion of $\mathrm{Ag}$ and Au NPs, respectively.
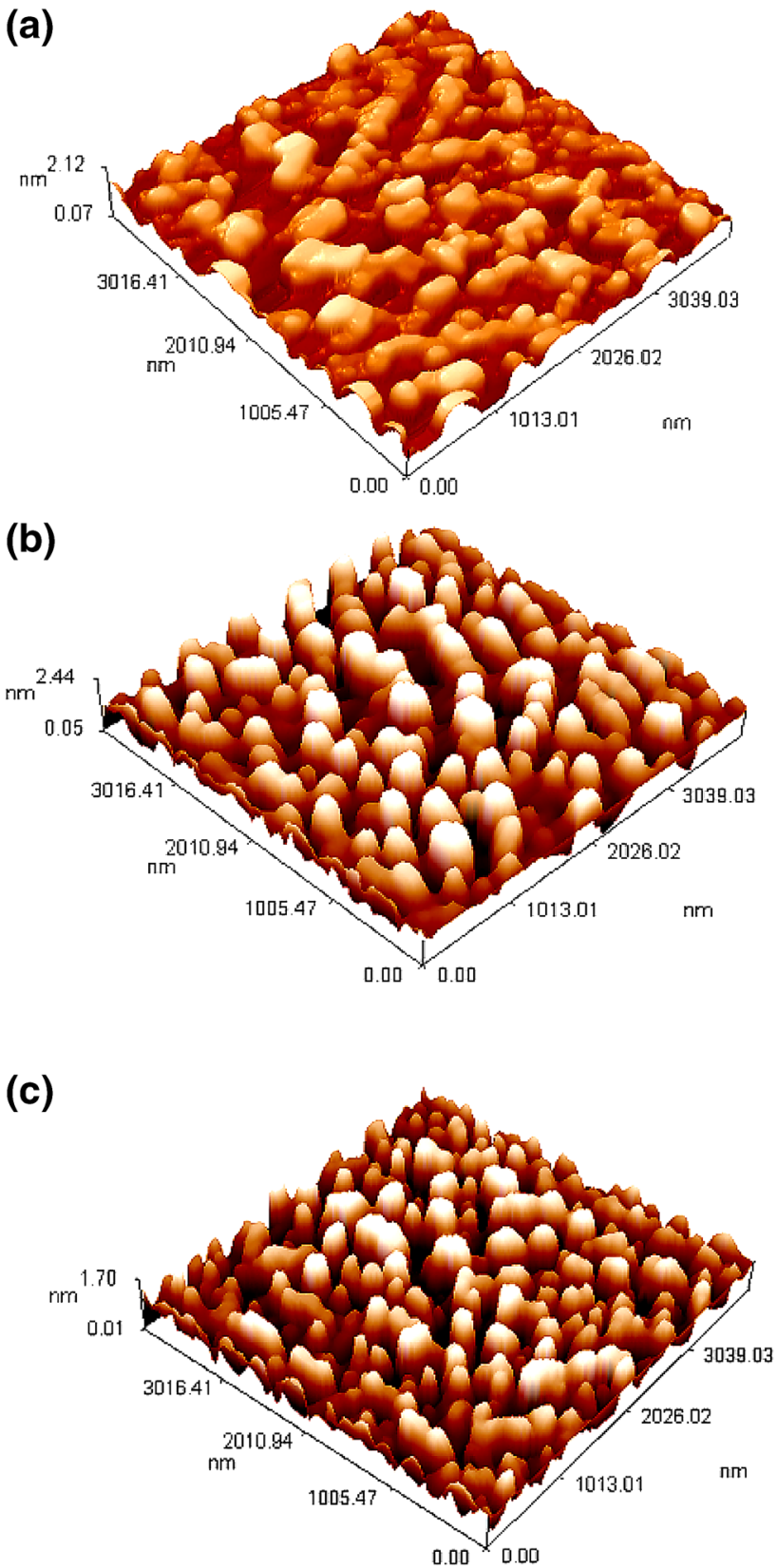

Fig. 7 3-D AFM images of PS (a), Au-PS composite (b) and Ag-PS composite (c) 
(a)

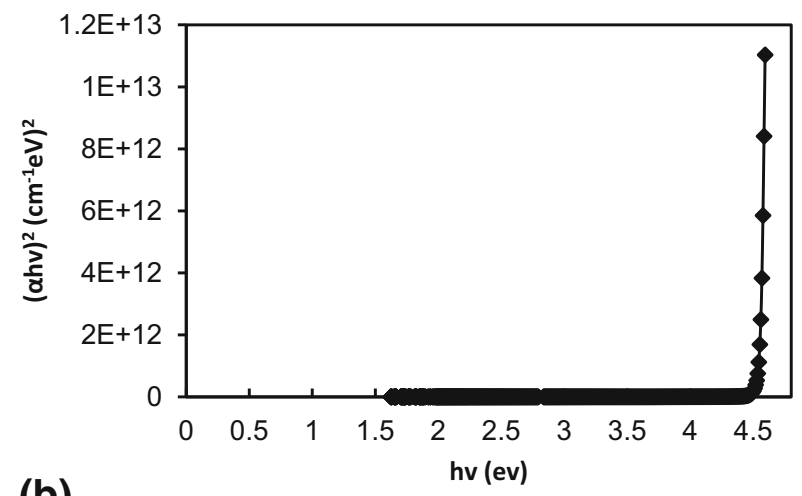

(b)

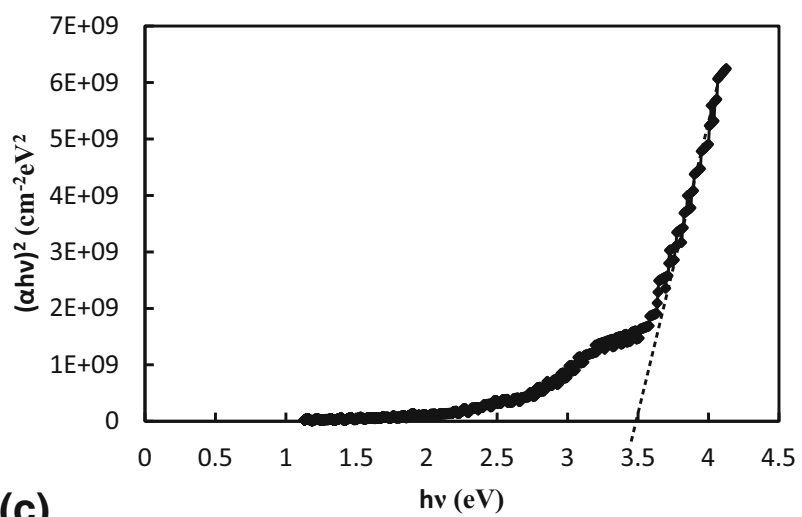

(c)

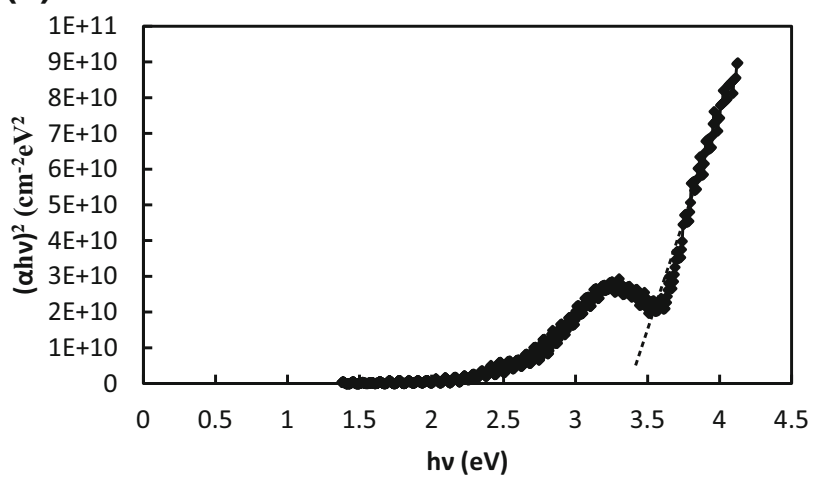

Fig. 8 Variation of $(\alpha h v)^{2}$ versus photo energy of PS, Au-PS and Ag-PS composites

This result can be ascribed to (I) appearance of loose defect charges located at interface and to (II) the conducting process is dominated by the percolating paths, in parallel with other non-percolating paths (Tchoul et al. 2008; Shockley and Read 1952).

The FT-IR spectra of PS, Au-PS composite and Ag-PS composite are shown in the Appendix, the IR transmission bands of PS correspond to their functional groups, $\mathrm{C}-\mathrm{H}$ aromatic stretch was noticed at the range $2924-3026 \mathrm{~cm}^{-1}$, peak located at $1600 \mathrm{~cm}^{-1}$ indexed to $\mathrm{C}=\mathrm{C}$ noticed, $\mathrm{C}=\mathrm{O}$ at $1745 \mathrm{~cm}^{-1}$, stretch $\mathrm{C}-\mathrm{O}$ bond located at $906 \mathrm{~cm}^{-1}$ and $\mathrm{CH}_{2}$ (wagging) at $1600 \mathrm{~cm}^{-1}$. The FT-IR of Au-PS composite and Ag-PS composite showed formation of the main PS functional groups, but the intensity of bond absorption peaks has increased and slight shifts in the wavenumber of main bonds was observed. The dark I-V characteristics of PS/p-Si, Au-PS/p-Si and $\mathrm{Ag}-\mathrm{PS} / \mathrm{p}-\mathrm{Si}$ heterojunctions are depicted in Fig. 9 under forward and reverse bias. Poor I-V characteristics were noticed for $\mathrm{PS} / \mathrm{p}-\mathrm{Si}$ heterojunction, attributed to the trapping and recombination centers that arose from porous structure of PS. The I-V of Au-PS composite/p-Si exhibits the following rectification characteristics: the rectification factor was found to be $\sim 71$ at $4 \mathrm{~V}$, the forward current increases with bias voltage and the reverse current was voltage independent at $V_{\mathrm{R}}<2 \mathrm{~V}$, soft breakdown was noticed after increasing the bias voltage beyond this voltage value. A typical I-V characteristic was noticed for Ag-PS/p-Si heterojunction, but breakdown occurred at $2.5 \mathrm{~V}$ which can be ascribed to the leakage current and surface states.

Figure 10 illustrates the illuminated $\mathrm{I}-\mathrm{V}$ characteristics of $\mathrm{PS} / \mathrm{Si}, \mathrm{Au}-\mathrm{PS} / \mathrm{Si}$ and $\mathrm{Ag}-\mathrm{PS} / \mathrm{Si}$ heterojunctions; the current increased after illumination due to generation of $\mathrm{e}-\mathrm{h}$ pairs in depletion region between the PS layer and Si substrate. The photocurrent for PS composite/Si heterojunctions was higher than that of PS/Si. This can be attributed to the light absorption enhancement originated by presence of Ag NPs and Au NPs throughout the surface plasmon resonance SPR process as well as due to increasing the electrical conductivity of PS layer (increasing the depletion layer width). On the other hand, increasing the light intensity leads to increasing the photocurrent and no saturation in photocurrent was noticed indicating good linearity characteristics of the synthesized photodetectors. The spectral responsivity plot of $\mathrm{PS} / \mathrm{Si}$ heterojunctions at $1.5 \mathrm{~V}$ bias is demonstrated in Fig. 11. It can be defined as the ratio of photocurrent to incident light power and depends on the numbers of $\mathrm{e}-\mathrm{h}$ pairs generated at or the vicinity of depletion region of the junction.

It is clearly noted that there are two peaks of response: the first peak (region 1) is located at $450 \mathrm{~nm}$ due to

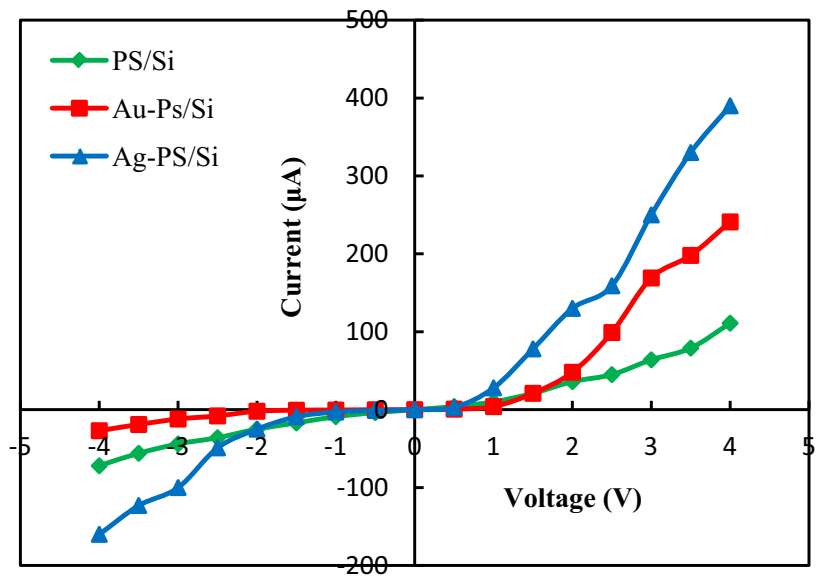

Fig. 9 Dark I-V characteristics of PS/Si heterojunctions before and after inclusion of Au NPs and Ag NPs 

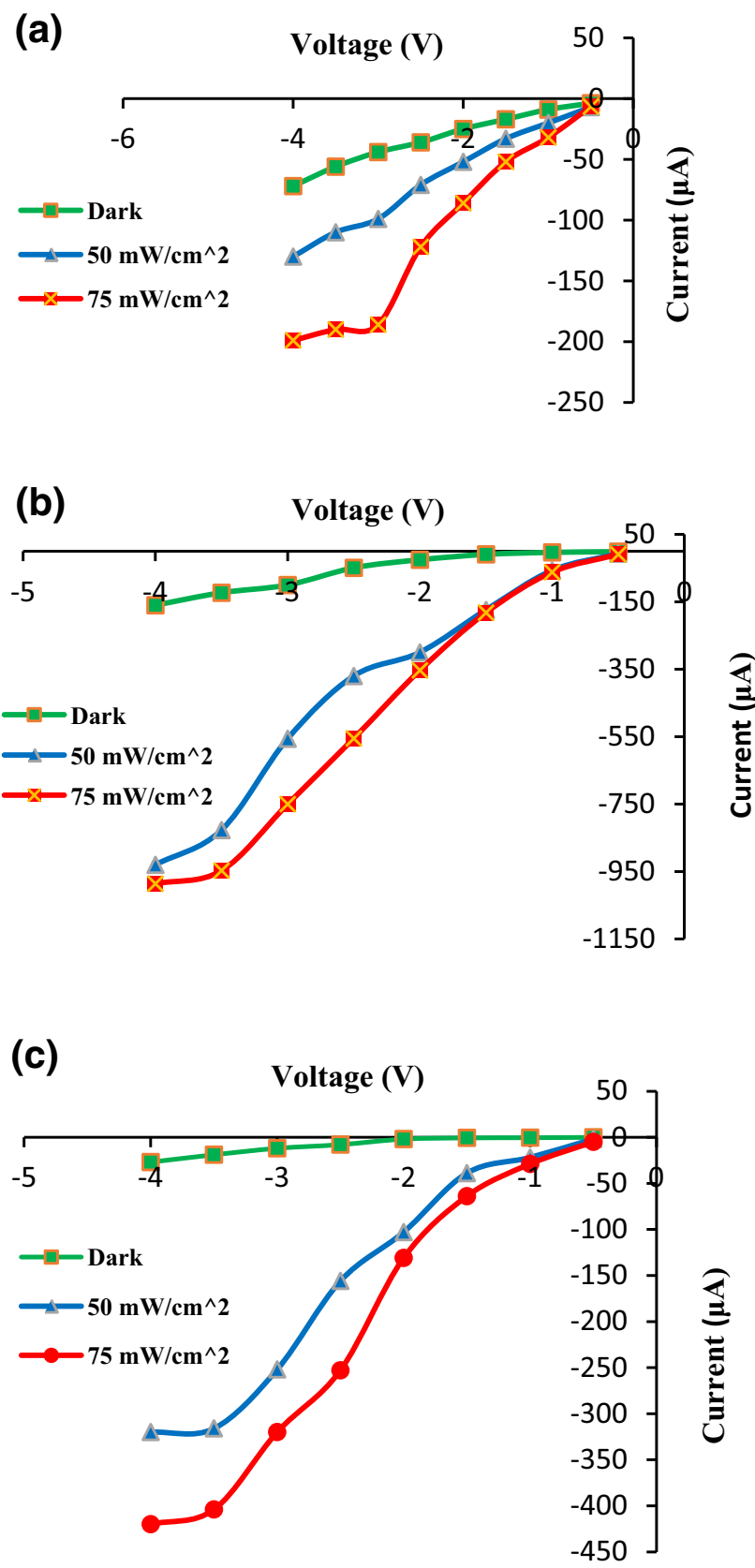

Fig. 10 Illuminated $\mathrm{I}-\mathrm{V}$ characteristics of $\mathrm{PS} / \mathrm{Si}$ (a) $\mathrm{Au}-\mathrm{PS} / \mathrm{Si}$ (b) and $\mathrm{Ag}-\mathrm{PS} / \mathrm{Si}$ heterojunctions (c)

absorption edge of PS, while the second peak is located at (800-900) $\mathrm{nm}$ (region 2) due to absorption edge of underlaying $\mathrm{Si}$ substrate. The responsivity decreases after $450 \mathrm{~nm}$ due to recombination process; the carriers which recombine before reaching the depletion region (high internal electric field region) as stated in the following equation (Shockley and Read 1952):

$U_{p}=\frac{p_{n}-p_{n 0}}{\tau_{p}}$,

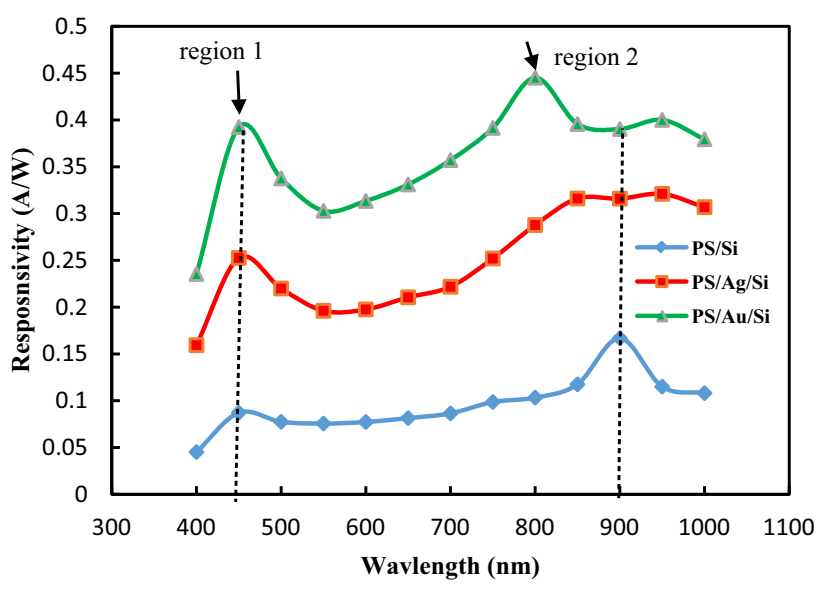

Fig. 11 Effect of inclusion of Au NPs and Ag NPs into PS matrix on spectral responsivity of heterojunctions

where $U_{n}$ is net recombination rate, $p_{n}$ is the concentration of holes in $n$-type and $p_{n 0}$ is the hole concentration at thermal equilibrium and $\tau_{\mathrm{p}}$ is the minority carrier life time. It can be seen that addition of the Au NPs and the Ag NPs into $\mathrm{PS} / \mathrm{Si}$ junction increases the responsivity by factor of 4 and 2.5 , respectively. This result can be attributed to the increase in light absorption by embedding of nanoparticles. The responsivity of $\mathrm{Au}-\mathrm{PS} / \mathrm{Si}$ and $\mathrm{Ag}-\mathrm{PS} / \mathrm{Si}$ heterojunctions was higher than that of PS/Si heterojunction due to increase in the sensitive area of photodetector of Ag- or Au-decorated PS microspheres. Increasing the depletion width of heterojunction after adding Ag NPs and Au NPs plays big role in improvement of the responsivity of heterojunction, particularly at the visible region (Ismail et al. 2013,2016).

\section{Conclusion}

We have successfully demonstrated a simple and novel technique to synthesis Ag-decorated and Au-decorated PS microspheres. The optical properties data show that the optical energy gap of PS decrease after incorporating with Au NPs and Ag NPs. XRD data confirm the amorphous nature of PS and PS composite layers. The electrical and photoresponse of PS/Si enhanced significantly after adding Ag NPs and Au NPs. Two peaks of response were noticed for PS composite/Si heterojunction. Based on the results obtained, this technique can be used to fabricate high photosensitivity and cost-effective PS/Si heterojunction photodetectors.

Open Access This article is distributed under the terms of the Creative Commons Attribution 4.0 International License (http:// creativecommons.org/licenses/by/4.0/), which permits unrestricted use, distribution, and reproduction in any medium, provided you give appropriate credit to the original author(s) and the source, provide a link to the Creative Commons license, and indicate if changes were made. 


\section{Appendix}

See Fig. 12.
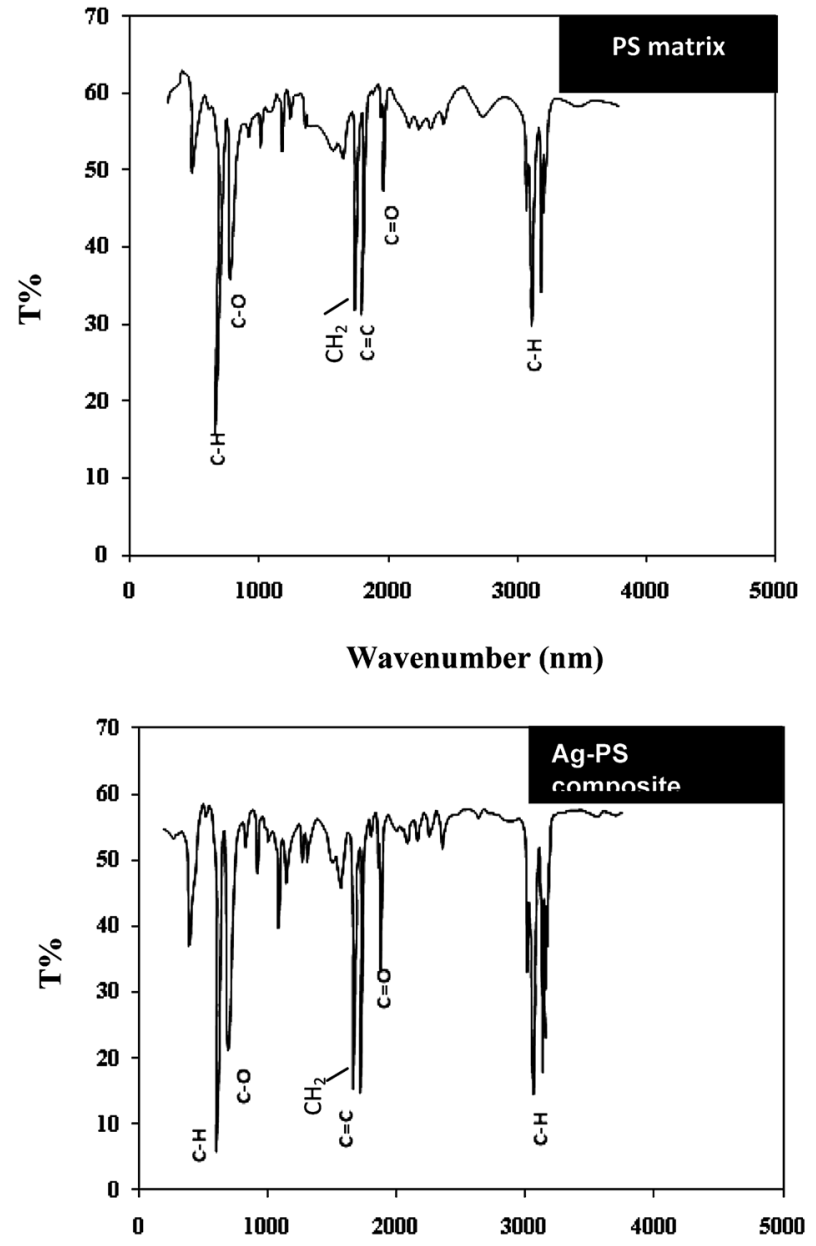

Wavenumber (nm)

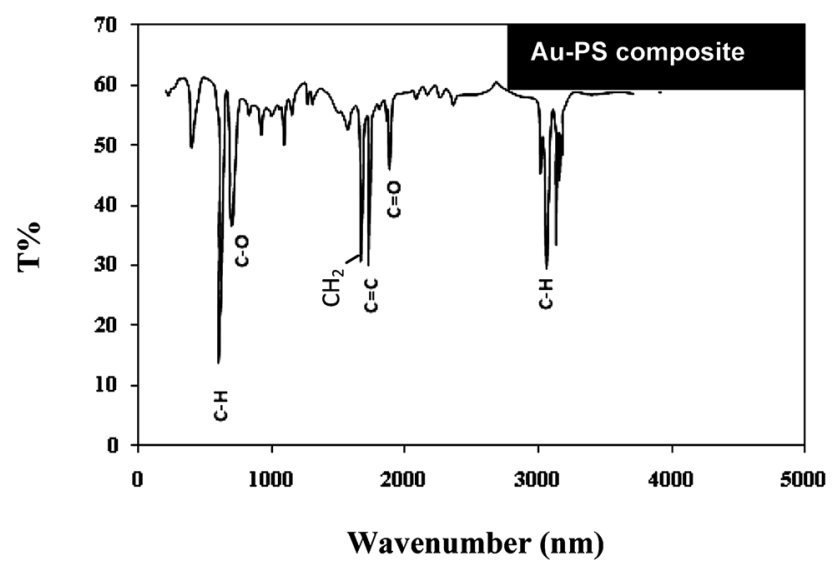

Fig. 12 FT-IR spectra of PS, Ag-PS composite and Au-PS composite

\section{References}

Ahmad T, Mamat O (2011) The development and characterization of zirconia-silica sand nanoparticles composites. World J Nano Sci Eng 1:7

Alekseeva O, Bagrovskaya N, Noskov A (2013) Polystyrene film composites filled with fullerenes. In: Proceedings of the international conference nanomaterials: applications and properties vol 2, 03NCNN24

Aly A, Mahmoud M, Omar A (2012) Enhancement in mechanical properties of polystyrene filled with carbon nano-particulates $\left(\mathrm{CNP}_{\mathrm{S}}\right)$. World J Nano Sci Eng 2:103

Costa L, Valente M, Henry F, Ramanitra L (1998) Electrical properties of the polymer composite polystyrene/iron particles. J Chim Phys 95:1453

Grant C, Schwartzberg A, Norman T Jr, Zhang J (2003) Ultrafast electronic relaxation and coherent vibrational oscillations of strongly coupled gold nanoparticle aggregates. J Am Chem Soc 125:549

Higuchi T, Sugimori H, Yabu H, Jinnai H (2016) Controlled incorporation behavior of gold nanoparticles into $\mathrm{ABC}$ triblock terpolymer with double-helical morphology. Polym J 48:509

Hsu C, Yang C, Wang Y, Huang C, Lien S, Kung C, Lou J (2016) Low Cost local contact opening by using polystyrene spheres spin-coating method for PERC solar cells. Materials 9:549

Ismail R, Ali A, Hasson K (2012) Characteristics of a silicon Schottky photodetector produced from colloidal gold nanoparticles. Micro Nano Lett 7:536

Ismail R, Ali A, Hassoon K (2013) Preparation of a silicon heterojunction photodetector from colloidal indium oxide nanoparticle. Opt Laser Technol 51:1

Ismail R, Alwan A, Ahmed A (2016) Preparation and characteristics study of nano-porous silicon UV photodetector. Appl Nanosci. doi:10.1007/s13204-016-0544-9

Khodary A (2010) Evolution of the optical, magnetic and morphological properties of PVA films filled with $\mathrm{CuSO}_{4}$. Phys B 405:3401

Khokhar A, Rahman F, Johnson N (2011) Preparation and properties of gold-infiltrated polystyrene photonic crystals. J Phys Chem Solids $72: 185$

Nikkeshi S, Kudo M, Masuko T (1998) Dynamic viscoelastic properties and thermal properties of powder-epoxy resin composites. J Appl Polym Sci 69:2593

Sangawar V, Golchha M (2013) Evolution of the optical properties of polystyrene thin films filled with zinc oxide nanoparticles. Int J Sci Eng Res 4:2700

Shaffer M, Koziol K (2002) Polystyrene grafted multi-walled carbon nanotubes. Chem Commun 18:2074

Sheikholeslami M (2017a) Magnetic field influence on nanofluid thermal radiation in a cavity with tilted elliptic inner cylinder. J Mol Liq 229:137

Sheikholeslami M (2017b) Numerical simulation of magnetic nanofluid natural convection in porous media. Phys Lett A 381:494-503

Sheikholeslami M, Vajravelu K (2017) Nanofluid flow and heat transfer in a cavity with variable magnetic field. Appl Math Comput 298:272

Sheikholeslami M, Hayat T, Alsaedi A (2017) Numerical study for external magnetic source influence on water based nanofluid convective heat transfer. Int J Heat Mass Transf 106:745

Shockley W, Read W (1952) Statistics of the recombinations of holes and electrons. Phys Rev 87:835

Sureshkumar M, Goyal R, Negi Y (2008) Potential applications of polystyrene in optoelectronics. Prog Rubber Plast Recycl Technol 24:53 
Tchoul M, Ford W, Ha M, Chavez-Sumarriva I, Grady B, Lolli G, Resasco D, Arepalli S (2008) Composites of single-walled carbon nanotubes and polystyrene: preparation and electrical conductivity. Chem Mater 20:3120

Walker JP, Asher SA (2005) Acetylcholinesterase-based organophosphate nerve agent sensing photonic crystal. Anal Chem 77:1596

Xia Z, Song T, Sun Lee J, Sun B (2014) Plasmonic enhancement in hybrid organic/Si heterojunction solar cells enabled by embedded gold nanoparticles. Appl Phys Lett 105:241110

Yong K, Sahoo Y, Swihart M, Prasad P (2006) Synthesis and plasmonic properties of silver and gold nanoshells on polystyrene cores of different size and of gold-silver core-shell nanostructures. Colloids Surf A Physicochem Eng Asp 290:89
Zhang Y, Gu C (2006) "Light induced further agglomeration of metal particles", Nanomanipulation with Light II. In: Andrews D (ed) Proceedings of SPIE, vol 6131, p 61310H

Zhang Y, Gu C, Schwartzberg A, Chen S, Zhang J (2006) Optical trapping and light-induced agglomeration of gold nanoparticle aggregates. Phys Rev B 73:165405

Zhu K, Schmauder S (2003) Prediction of the failure properties of short fiber reinforced composites with metal and polymer matrix. Comput Mater Sci 28:743

Zhu W, Wu Y, Yan C, Wang C, Zhang M, Wu Z (2013) Facile synthesis of mono-dispersed polystyrene (PS)/Ag composite microspheres via modified chemical reduction. Materials 6:5625 